\title{
Socio-economic Assessment of Inhabitants of Residential Densities in Akure, Nigeria
}

\author{
Gabriel Emmanuel ${ }^{*}$, Fasakin, J. 0. \\ Department of Urban and Regional Planning, Federal University of Technology, Nigeria
}

Copyright@2017 by authors, all rights reserved. Authors agree that this article remains permanently open access under the terms of the Creative Commons Attribution License 4.0 International License

\begin{abstract}
This paper examines socio-economic attributes of inhabitants in residential densities in Akure, Nigeria. The research investigated the sex, age, education, marital status, household size, occupation and level of income of the respondents. The sample size of 1,134 respondents was distributed in the proportion of 567; 425 and 142 , for the core, transition and peripheral zones respectively. Sex of respondents varies from one zone to the other. Age shows that there is more of productive age than the dependent citizens while without formal education accounted for $12.8 \%$ within the study area. Seventy-nine percent were married inhabitants and $12.1 \%$ single, while 4 to 6 number of members of families had the highest percentage. Most people residing at the heart of the city of Akure were business men/women (49.3\%) and craftsmen/others (34.4\%) and general monthly income is low with $37.8 \%$ of respondents earning less than $\$ 20,000$ per month. Consequently, the research work recommends poverty alleviation schemes, establishment of skill acquisition centres and housing loan/subsidies among others.
\end{abstract}

Keywords Socio-economic, Characteristics, Inhabitants and Housing Loan/Subsidies

\section{Introduction}

The rate of urbanization in Nigeria has witnessed tremendous increase in the last two decades. Census in the early fifties showed that, there were about 56 cities in the country and about $10.6 \%$ of the total population lived in these cities. This rose dramatically to $19.1 \%$ in 1963 and $24.5 \%$ in 1985 . The national population was estimated to be about 150 million with the urban population constituting about 30\% [1]. The rapid growth rate of urban population in Nigeria since the early seventies was mainly due to immigration induced by the concentration of the gains from the oil sector in the urban areas [2]. Given the expected increase in urban population, the magnitude of housing problem in the country was enormous.
Housing accounts for more than $70 \%$ of land use in most cities and determines urban form and densities, also providing employment and contributing to growth. In 2010, as many as 980 million urban households lacked decent housing, as will another 600 million between 2010 and 2030 . One billion new homes are needed worldwide by 2025, costing an estimated $\$ 650$ billion per year, or US \$9-11 trillion overall. In addition, shortages in qualitative deficiency are much larger than those in quantity [3]. Residential densities comprises of the low, medium and high densities, however, people of high educational attainment are highly status conscious. Besides, these people often seek for residential locations that satisfy their desires for prestigious dwellings and neighbourhoods comparable to their jobs, their incomes as well as their personality [4]. Socioeconomic characteristics are identified to include income, household size, education, age and employment status among others. These socioeconomic characteristics of the people are indicators of their quality of life [5]. Socio-economic characteristics of respondents are general variables that are germane to social policy-oriented research. They are designed to portray the personality profile of respondents $[6,7]$.

Moreover, this study examines the socio-economic attributes of residents living in the high, medium and low density areas of Akure. This is because housing embraces the day-to-day living and activities of individuals and families within the community. The research investigated the sex, age, education, marital status, household size, occupation and level of income of the respondents at the core, transitional and peripheral zones of the study area. However, suggestions were proffered to improve the socioeconomic dilemma of the inhabitants in the study area.

\section{Materials and Methods}

\subsection{The Study Area}

The study area is Akure, a Nigerian city, which like other traditional Yoruba towns in the country, has been in 
existence long before the advent of British colonial rule and modern planning standards and practices. The city is located within Ondo State in the South Western part of Nigeria, one of the 36 states of Nigeria. It lies approximately on latitudes $7^{0} 5^{1}$ and $8^{\circ} 00^{1}$ North of the Equator and longitude $5^{0} 45^{1}$ East and longitude $6{ }^{\circ} 00^{1}$ East of the Greenwich Meridian at an altitude of $370 \mathrm{~m}$ above sea level. Akure is a medium-sized urban centre that became the provincial headquarters of old Ondo province in 1939. It also became the capital city of Ondo State and a Local Government Headquarters in 1979. These dual political roles of Akure have since acted as impetus to the influx of people into the city [8].

Akure is located approximately 700 kilometers South West of Abuja, the Federal Capital of Nigeria and about 350 kilometers to Lagos, the former capital of Nigeria. It is located within the tropical rain forest region of Nigeria where rainfall is high throughout the year. The increased relative political influence of Akure as a state capital since 1976 has greatly promoted its rapid growth and socio-economic activities resulting in its spatial expansion from an area of about 16 square kilometers in 1980 to about 30 square kilometers in 2000. The population of the city grew from 38,852 in 1952 to 71,106 in 1963 . Its population was estimated to be 112,850 in 1980); and 157,947 in 1990 (Ondo State of Nigeria, 1990). The 1991 national population census however, puts the population of Akure at 239,124 and its population in 2006 was 353,211 [9]. At 2014, using a growth rate of 3.18 percent, the city was estimated to have 453,731 people using a formula for projection, $\mathrm{Pt}=\mathrm{Po}(1+\mathrm{r})^{\mathrm{n}}$ [7]. However, the study area is divided into three neighbourhoods which include the core, transitional and peripheral zones.

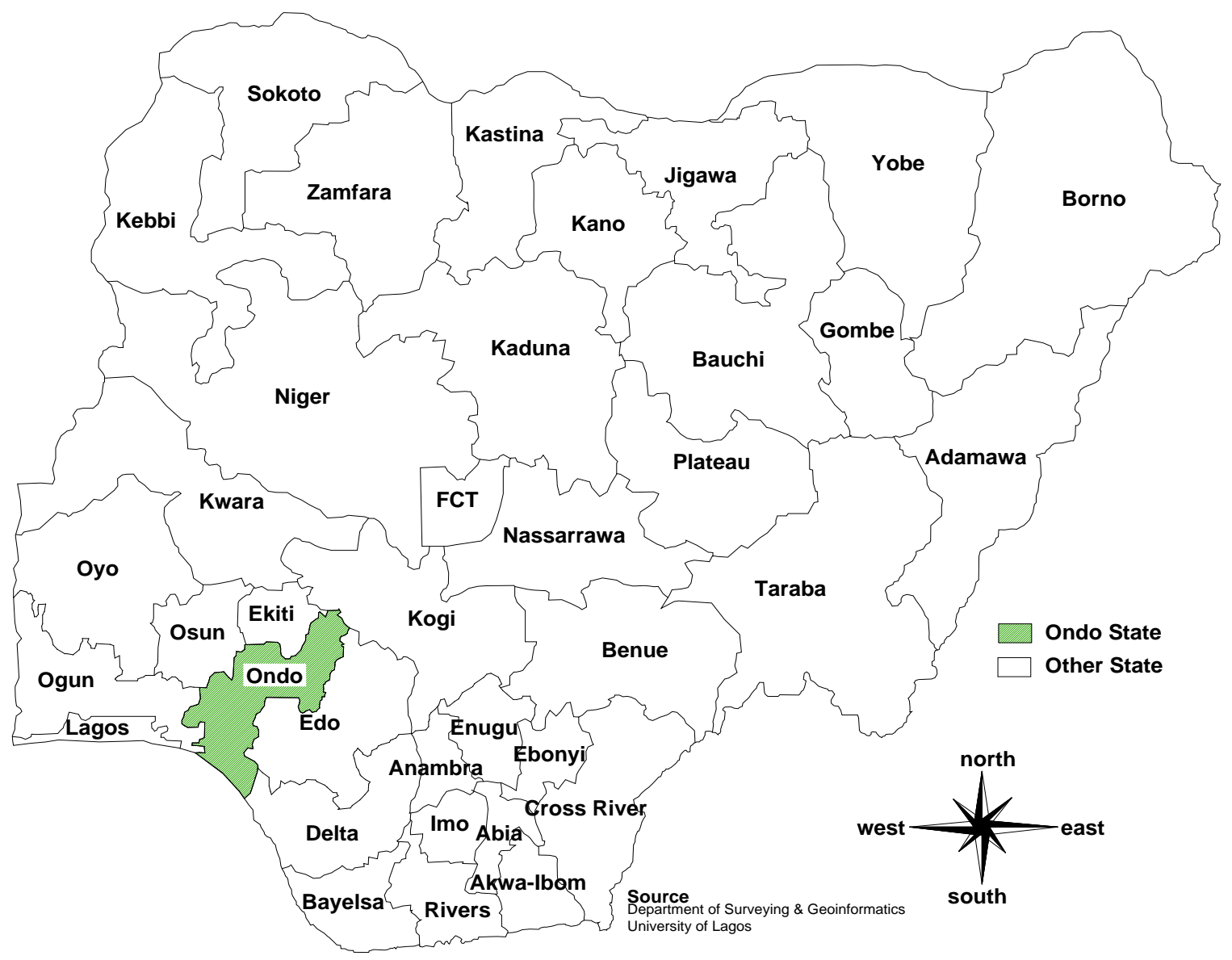

Source: Department of Surveying \& Geoinformatics, University of Lagos, (2016).

Figure 1. The study area in its national setting 
Primary data for the study were generated from the administration of a structured questionnaire. The questionnaire focused on household heads or any adult living in the buildings within the study area. It investigated among other things; sex, age, education, marital status, household size, occupation and level income of the respondents. Secondary data were obtained from the Ministry of Lands and Housing, Ondo State Development and Property Corporation, Physical Planning Department and Survey Department in Ministry of Works Akure, Ondo State, while Property Maps were obtained from the National Population Commission among others.

The population of Akure according to the 2006 population census was 353,211 [9]. This was projected to 2014 using $3.18 \%$ annual growth rate officially determined by the National Population Commission. The city was estimated to have 453,731 people. The total number of buildings in Akure was calculated to be 16,205 , using the following formula, where ppf and hpb are persons per family and households per building.

$\frac{\text { Current Population Figure }}{7(p p f) \times 4(h p b)}=\frac{453,731}{28}=16,205$ buildings

A sample size of $7 \%$ was used for questionnaire administration that gave 1,134 respondents. This proportion was reasonable given the homogeneity characterizing the study area which includes, form and age of buildings, physical conditions of housing units, condition of neighbourhood infrastructure and respondents personal profile among others. Using the table of random numbers, 24 Enumeration Areas (EAs) were selected on the ratio of 50:35:15 for the core; transition and peripheral zones from the 2006 EAs from the NPC [10]. Twelve (12) EAs were sampled for the core; 9 for the transition zone; and 3 for the peripheral zone. The sample size of 1,134 respondents was distributed in the proportion of 567; 425; and 142 for the core, transition and peripheral zones respectively. A total of 831 representing $73.28 \%$ out of the total 1,134 questionnaires administered were retrieved and used for analysis. The selection of twenty-four (24) EAs was reasonable, when earlier studies were considered that utilized EAs.

For instance, the Federal Ministry of Health [Nigeria], 2003 used two EAs per Local Government; and the National Population Commission [Nigeria], used the same number of EAs for 2008 National Demographic and Health Survey. Twenty field assistants were employed to administer the questionnaire in three months. Tables and graphs were used to present, interpret and discuss research findings through SPSS version 21 and Microsoft Excel 2013.

\subsection{Definition of Research Variables}

As the basis for empirical investigation and analysis, there is a need to embark not only on listing of research variables, but also to present the definition, that is, to explain the meaning, provide justification and rationale for including each of the research variables [6]. Definition of variable involves essentially:

(i) Clarification of the meaning of the variable, that is, what it is.

(ii) Derivation of code for each variable for easy reference in data analysis and interpretation.

(iii) Specification of measurement scale, that is, various options to each question in the questionnaire.

(iv) Careful exposition of typical or international units of measurement like "N" for Naira, " $€$ " for Euro and “m” for metre.

(v) Specification of time frames for some variables, for example, yearly, monthly, weekly, daily, hourly and so on.

For the purpose of this research, however, variables have been identified based on socio-economic characteristics of respondents in the study area. Thus, the research variables are as identified and described.

\subsubsection{Definition of Variables on Socio-economic Background of Respondents}

The variables on socio-economic characteristics of respondents include: SEX, AGE, EDU, MARITA, H-SIZE, OCCUPA, and INCOME for sex, age, education, marital status, household size, occupation and income level of the respondents in the study area respectively. These variables were used to assess the validity of the data used in the study area. For instance, the lowest age cohort for this study is 20-29 years. This shows that the questionnaire was administered to adults in the study area. Although INCOME is part of socio-economic variables, in this research it is considered important. The average monthly income of the respondents reveals their capability of building a personal house. EDU is pertinent, because information gathered from literate community is reliable. The average household size (H-SIZE) reveals the crowding index in the study area.

Level of measurement refers to the particular way that a variable is measured, and scale of measurement refers to the particular tool for sorting the data that one applies based on the level. Choosing level and scale of measurement is an important part of the research design process because they are necessary for systematized measuring and categorizing of data, and thus for analyzing it and drawing conclusions from it as well [11]. Descriptive statistics summarize data. The mean of the variable is the arithmetic average of the scores, calculated by adding all the scores and dividing by the total number of scores. On the other hand, the standard deviation of the variable provides some idea about the distribution of scores around the mean (average). The smaller the standard deviation, the more narrow the range between the lowest and highest scores or, more generally, that the scores cluster closely to the average score. It is a measure of "agreement" between raters. If everyone gave the same score, then the standard deviation would be zero and the agreement would be high (or perfect) among the 
respondents.

Sex as a variable shows that women prefer their husbands to be interviewed, as revealed by the findings of this study. This was because of suspicion, skepticism and misinterpretation of the exercise, thinking it was meant to determine taxable adults. It revealed the speculation that, there were increasing numbers of male populations moving from the core to the periphery. Age revealed the distribution of the respondents in the study area. Household size showed the number of person(s) living in a house and eating from the same source (under the same household head). Occupation revealed the proportion of the respondents working as civil servants and those that are private among others.

\section{Results and Discussion}

\subsection{Introduction}

This section examines the analysis of socio-economic characteristics of the respondents in the residential densities within Akure city. The results are presented as shown in the following tables and charts.

Table 1. Specification, Coding and Measurement of Socio-economic Variables

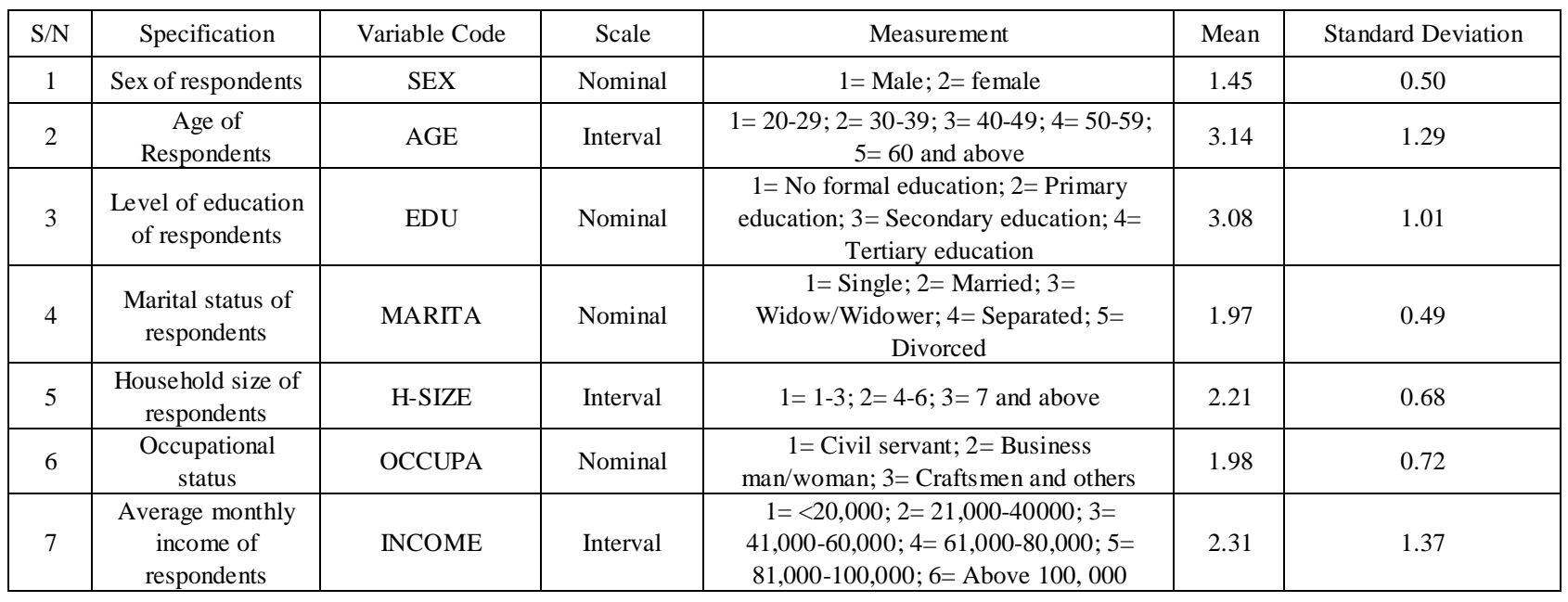

Source: Author’s Fieldwork, 2016.

Table 2. Sex of Respondents in Residential Densities of Akure

\begin{tabular}{|c|c|c|c|c|c|c|c|c|}
\hline \multirow{2}{*}{ Zone } & \multicolumn{2}{|c|}{ Core } & \multicolumn{2}{c|}{ Transition } & \multicolumn{3}{c|}{ Periphery } \\
(Study Area)
\end{tabular}

Source: Author's Fieldwork, 2016.

Table 3. Level of Education of Respondents in Residential Densities of Akure

\begin{tabular}{|c|c|c|c|c|c|c|c|c|}
\hline \multirow{2}{*}{$\begin{array}{c}\text { Zone } \\
\text { Level of Education }\end{array}$} & \multicolumn{2}{|c|}{ Core } & \multicolumn{2}{|c|}{ Transition } & \multicolumn{2}{|c|}{ Periphery } & \multicolumn{2}{|c|}{$\begin{array}{c}\text { Total } \\
\text { (Study Area) }\end{array}$} \\
\hline & Freq. & Percent (\%) & Freq. & Percent (\%) & Freq. & Percent (\%) & Freq. & Percent (\%) \\
\hline No formal education & 77 & 18.2 & 29 & 10.0 & 0 & 0 & 106 & 12.8 \\
\hline Primary education & 43 & 10.2 & 28 & 9.7 & 0 & 0 & 71 & 8.5 \\
\hline Secondary education & 175 & 41.5 & 110 & 38.1 & 21 & 17.5 & 306 & 36.8 \\
\hline Total & 422 & 100.0 & 289 & 100.0 & 120 & 100.0 & 831 & 100.0 \\
\hline
\end{tabular}

Source: Author's Fieldwork, 2016 
Table 4. Marital Status of Respondents in Residential Densities of Akure

\begin{tabular}{|c|c|c|c|c|c|c|c|c|}
\hline \multirow{2}{*}{ Marital Status } & \multicolumn{2}{|c|}{ Core } & \multicolumn{2}{|c|}{ Transition } & \multicolumn{2}{|c|}{ Periphery } & \multicolumn{2}{|c|}{ Total } \\
\hline & Freq. & Percent (\%) & Freq. & Percent (\%) & Freq. & Percent (\%) & Freq. & Percent (\%) \\
\hline Single & 45 & 10.7 & 52 & 18.0 & 4 & 3.3 & 101 & 12.1 \\
\hline Married & 323 & 76.5 & 226 & 78.2 & 115 & 95.8 & 664 & 79.9 \\
\hline Widow/Widower & 48 & 11.4 & 11 & 3.8 & 1 & .8 & 60 & 7.2 \\
\hline Separated & 3 & .7 & - & - & - & - & 3 & .4 \\
\hline Divorced & 3 & .7 & - & - & - & - & 3 & .4 \\
\hline Total & 422 & 100.0 & 289 & 100.0 & 120 & 100.0 & 831 & 100.0 \\
\hline
\end{tabular}

Source: Author's Fieldwork, 2016.

Table 5. Household Size of Respondents in Residential Densities of Akure

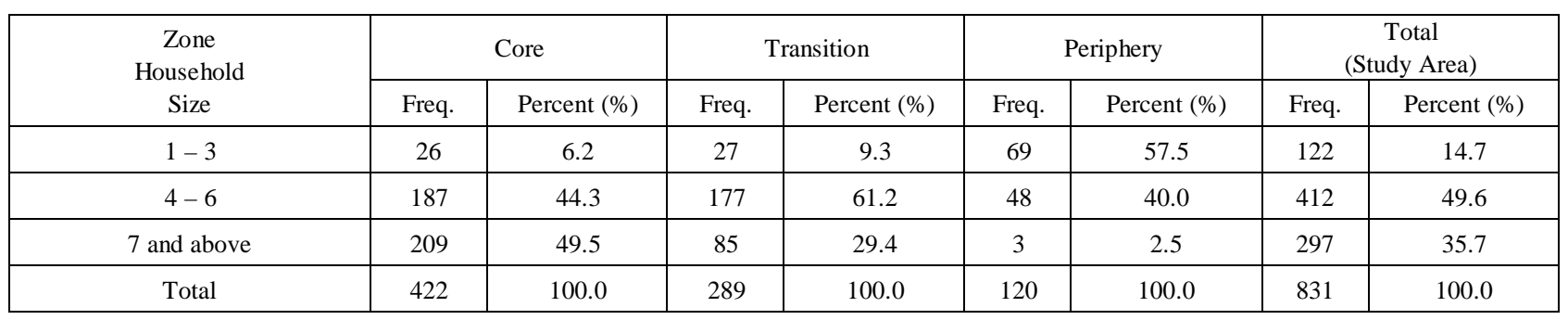

Source: Author’s Fieldwork, 2016.

Table 6. Occupation of Respondents in Residential Densities of Akure

\begin{tabular}{|c|c|c|c|c|c|c|c|c|}
\hline \multirow{2}{*}{$\begin{array}{c}\text { Zone } \\
\text { Occupation }\end{array}$} & \multicolumn{2}{|c|}{ Core } & \multicolumn{2}{|c|}{ Transition } & \multicolumn{2}{|c|}{ Periphery } & \multicolumn{2}{|c|}{$\begin{array}{c}\text { Total } \\
\text { (Study Area) }\end{array}$} \\
\hline & Freq. & Percent (\%) & Freq. & Percent (\%) & Freq. & Percent (\%) & Freq. & Percent (\%) \\
\hline Business man/woman & 208 & 49.3 & 147 & 50.9 & 49 & 40.8 & 404 & 48.6 \\
\hline Craftmen and others & 145 & 34.4 & 58 & 20.1 & 3 & 2.5 & 206 & 24.8 \\
\hline
\end{tabular}

Source: Author's Fieldwork, 2016.

Table 7. Income of Respondents in Residential Densities of Akure

\begin{tabular}{|c|c|c|c|c|c|c|c|c|}
\hline \multirow{2}{*}{ Monthly Income } & \multicolumn{2}{|c|}{ Core } & \multicolumn{2}{|c|}{ Transition } & \multicolumn{2}{|c|}{ Periphery } & \multicolumn{2}{|c|}{ Total } \\
\hline & Freq. & Percent (\%) & Freq. & Percent (\%) & Freq. & Percent (\%) & Freq. & Percent (\%) \\
\hline$<20,000$ & 193 & 45.7 & 121 & 41.9 & - & - & 314 & 37.8 \\
\hline $21,000-40,000$ & 125 & 29.6 & 67 & 23.2 & 21 & 17.5 & 213 & 25.6 \\
\hline $41,000-60,000$ & 60 & 14.2 & 39 & 13.5 & 24 & 20.0 & 123 & 14.8 \\
\hline $61,000-80,000$ & 25 & 5.9 & 44 & 15.2 & 52 & 43.3 & 121 & 14.6 \\
\hline $81,000-100,000$ & 14 & 3.3 & 9 & 3.1 & 12 & 10.0 & 35 & 4.2 \\
\hline Above 100,000 & 5 & 1.2 & 9 & 3.1 & 11 & 9.2 & 25 & 3.0 \\
\hline Total & 422 & 100.0 & 289 & 100.0 & 120 & 100.0 & 831 & 100.0 \\
\hline
\end{tabular}

Source: Author’s Fieldwork, 2016.

\subsection{Sex of Respondents}

The pattern of results varies from one zone to the other. At the core 52.1 percent of the respondents were males against 47.9 percent females. Also in the transition zone, 55.0 percent of the respondents were males while 45.0 percent were females. At the periphery, it was discovered that 64.2 percent of the respondents were males while 35.8 percent were females. In an exploratory manner, the prominence of the male gender in the study area could be attributed to the fact that women in most cases prefer that, their husbands respond to interviews whether they are available or not. However, most of the respondents, misconstrued the exercise as a survey to determine taxable adults, and therefore the reference to the head of household in most cases. In addition, investigation revealed that the males were saddled with the responsibilities of provision and maintenance of basic 
facilities across the residential zones more than their females' counterparts. The results also revealed an increasing number of male populations from the core to the periphery.

\subsection{Age of Respondents}

The findings revealed that the age cohort 40-49 years had the highest proportion of 29.2 percent and indeed the age bracket with highest ratio across the residential zones in the study area. This was followed by respondents within the age bracket 30-39 with 25.6 percent. The age cohort with the least proportion is 20-29 years which accounted for 9.4 percent of the total respondents. Below 20 years age cohort was excluded because the research was designed to gather information from adults in the study area. The implication of the findings was that, there was more of productive age than the dependency ratio among the adults within the study area.

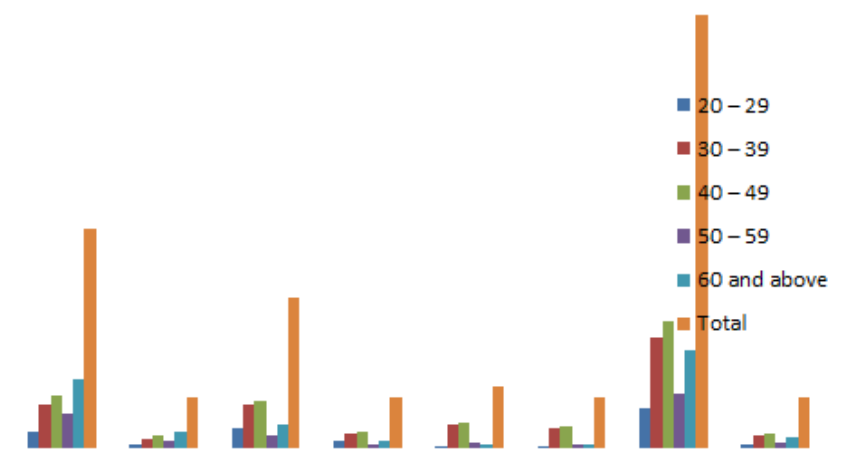

Source: Author’s Fieldwork, 2016.

Figure 3. Age of Respondents

\subsection{Education of Respondents}

The educational attainment of the heads of household is important. This is because household heads with some formal education are likely to do more in provision of housing infrastructure independent of Government. No doubt, education is a critical factor in the appreciation of up to date issues pertinent to urban studies as one can easily rely on information supplied by the literates [12]. This category of respondents has better sense for comfort and taste. The educational level of residents of Akure is shown in table 3. The table revealed that respondents without formal education accounted for 12.8 percent in the study area, having their enclaves at the core and transitional zones. While those with tertiary education were 41.9 percent most of whom were residents at the peripheral zone of Akure.

Spatially, at the core, highest level of education was 41.5 percent for secondary education and the lowest was primary education which had 10.2 percent. However, it is interesting to state that the result revealed that $30.1 \%$ had tertiary education in this zone. In the transition, tertiary education had 42.2 percent while the lowest was 9.7 percent for primary education. The residents at the periphery that had tertiary education were 82.5 percent while those with secondary education 17.5 percent (this is the zone where civil servants reside most; it is the neighbourhood where the elites of the city live). The results in table 2 revealed that educational attainment increased from primary education to tertiary education both at the transition and periphery while the reverse was the case in the core of the study area. The implication of this is that there were more literate inhabitants at the transitional and peripheral zones. Therefore, the low level of education of some respondents in the study area may undermine the importance of housing quality.

\subsection{Marital Status of Respondents}

The marital status of the respondents revealed that 79.9 percent were married and 12.1 percent single in the entire study area. It was observed that at the core, 0.7 percent and 0.7 percent were separated and divorced respectively. At the transitional zone, 78.2 percent of the respondents were married and 3.8 percent were widows/widowers. In addition, at the periphery, findings revealed that 95.8 percent of the respondents were married and 3.3 percent were single. Although, the status of those married was high across the residential zones but highest at the periphery.

\subsection{Household Size of Respondents}

Household size is the number of inhabitants residing in a housing unit whose production of income and consumption of goods and services are related. The household sizes of the respondents were studied across the residential zones in the study area. The study revealed that 49.6 percent of the respondents in the study area had household size of four to six persons. At the core, the findings revealed that 7 and above persons per household had the highest proportion of 49.5 percent and the lowest was one to three household size with 6.2 percent. Within the transitional zone, results showed that four to six had the highest household size which accounted for 61.2 percent and this was followed by seven and above making up to 29.4 percent. However, at the periphery, findings revealed that 57.5 percent of the respondents had a household size of one to three persons and this was followed by 40.0 percent for household size of four to six persons per housing unit. Moreover, the findings of this research revealed that, 4 to 6 household size had the highest percentage. Therefore, the finding concurs with the result of [13] which states that the average household size in Ondo State was 6 persons per household.

\subsection{Occupation of Respondents}

The occupational composition showed the differences in types and representations across the residential zones. Findings revealed that most people residing at the heart of the city of Akure were business men/women having 49.3 percent and craftsmen/others 34.4 percent. At the transition, business men/women accounted for 50.9 percent and 29.1 percent of the respondents were civil servants. Furthermore, 
the findings revealed that at the peripheral zone, civil servants and business men/women had 56.7 percent and 40.8 percent respectively. It is therefore deduced that the self-employed and craftsmen are resident at the city core while greater percentage of the civil servants in the study area are resident at the periphery

\subsection{Monthly Income of Respondents}

Findings in table 7 showed the monthly income of respondents across the residential zones. At the core, there was a constant decrease in the monthly income. That is, from less than $\$ 20,000$ per month to above $\$ 100,000$ a month and this accounted for 45.7 percent to 1.2 percent respectively. While at the periphery the reverse is the case, it was observed that there is stable increase upward in the monthly income hierarchy. However, at the transition zone, it was observed that there was a decrease in the monthly income of respondents from less than $\$ 20,000$ to between $\$ 41,000$ and \#60,000 which accrued for 41.9 percent to 13.5 percent respectively.

Investigation revealed that the general monthly income is low with $37.8 \%$ of respondents earning less than $¥ 20,000$ per month. With this low income distribution, to afford good housing would be difficult, if not impossible. However, this is important to this research, because with higher income, there is more disposable income with which to procure decent housing. In addition, the finding of this study shows that the poorer residents are more in the high density area that are also considered as low and medium income earners. The implication of this is that the low and medium income earners may not be able or would find it difficult to save enough money to buy or build their own houses. This discovery tallies with the findings of [14] on housing finance in Akure, Ondo State, which also revealed that low and medium income earners would find it difficult to build their own house.

\section{Conclusions}

It is an undeniable reality that the residential nature of a town or city is functionally related to the location and decisions of the inhabitants in the community. From the analysis of this study, it was revealed that there seems to be an increasing number of male populations from the core to the periphery and there is more of productive age than the dependency ratio within the study area. The low level of education of some respondents in the study area undermined the importance of housing quality. The findings of this study also revealed that the status of those married is high across the residential zones but highest at the periphery. However, self-employed and craftsmen are resident at the city core while greater percentage of the civil servants in the study area are resident at the periphery. Apparently, low and medium income earners may not be able or would find it difficult to save enough money to buy or build their own houses. Therefore, this paper recommends poverty alleviation scheme, [15] report suggests two strategies. These are: 1. Promotion of the productive use of the poor's most abundant asset-labour. This invariably calls for policies that create market incentives, stable social and political institutions, good infrastructure and adaptable technology. 2. Making basic social services available to the poor. Hence primary health care, family planning, balanced nutrition and primary education are of prime importance. Also economic growth remains the primary means of reducing poverty and improving the quality of life. Therefore economic policies should be directed towards poverty reduction, such as increased sectoral allocation to the productive sectors of the economy in order to create more jobs and raise the level of employment. Unemployment is perceived as a key part of poverty [16]. Establishment of skill acquisition centres for training on masonry, carpentry, arts and crafts, decoration, electrical installation, information communication technology (ICT), wood works, welding, metal works, spray and painting, in addition, housing loan/subsidies, site and service to improve the socioeconomic predicament of the inhabitants of the study area.

\section{REFERENCES}

[1] J. O. Ajanlekoko, (2011). Construction development bank: A panacea for affordable housing and infrastructural development in Nigeria. A paper Delivered at the $4^{\text {th }}$ Annual Lecture of the School of Environmental Technology, Federal University of Technology, Akure, Ondo State.

[2] K. Oyesiku, (2009): City Liveability: implications and challenges. Paper presented at the 2009 Commonwealth Association of Planners, West Africa Workshop on Planning for Liveable Human Settlement: The West African Challenges, Lagos.

[3] UN-HABITAT, (2016). Urbanisation and development: Emerging futures. World Cities Report, 2016. www.unhabitat.org

[4] O. G. Julius, and L. R. Momoh, (2009). Residents' socio-economic characteristics and the residential mobility process in an urban space: The example of the Warri metropolis, Delta State, Nigeria. Journal of Hum Ecol, 27(1), 45-52.

[5] O. O. Rotowa, J. A. B., Olujimi, F. K., Omole, and A. E. Olajuyigbe, (2015). Socioeconomic factors affecting household's sanitation preferences in Akure, Nigeria. European International Journal of Science and Technology 4(5), 183-194.

[6] J.O. Fasakin, (2000). A land use analysis of the operation of commercial motorcycles in Akure, Nigeria. Unpublished $\mathrm{PhD}$ Research Thesis, Department of Urban and Regional Planning, Federal University of Technology, Akure, Nigeria.

[7] E. Gabriel, (2017). Spatial differentiation of housing 
infrastructure autonomy in Akure, Nigeria. Unpublished PhD Research Thesis, Department of Urban and Regional Planning, Federal University of Technology, Akure, Nigeria.

[8] J. A. B. Olujimi and I. O. Olamiju (2011). Regional analysis of locations of public educational facilities in Nigeria: The Akure region experience. Journal of Geography and Regional Planning 4(7), 428-442. Available online at http://www.academicjournals.org/JGRP.

[9] National Population Commission, (2006). Population and housing census: "Population distribution by Sex, State, LGA, and Senatorial district", http://www.population.gov.ng/images.

[10] O. O. Rotowa, (2014). Spatio-environmental management of faecal waste in the residential zones of Akure, Nigeria. Unpublished PhD Research Thesis, Department of Urban and Regional Planning, Federal University of Technology, Akure, Nigeria.

[11] A. Crossman, (2017). Understanding levels and scales of measurement: Nominal, ordinal, interval, and ratio with examples.

https://www.thoughtco.com/scales-of-measurement-3026571.

[12] TETFUND, University Research Grant. (2017). E-land pricing in residential housing density mix in Akure, Nigeria. Federal University of Technology, Akure, Nigeria.

[13] National Population Commission (2006). Population and housing census: "Population distribution by Sex, State, LGA, and Senatorial district", http://www.population.gov.ng/images.

[14] A. Olumide, (2015). Housing finance in urban areas of Nigeria: An empirical example from Akure, Ondo State. Swift Journals of Social Sciences 1(1), 8-12.

[15] World Bank (1996). Nigeria: Poverty in the midst of plenty. The challenge of growth with inclusion. Washington DC: World Bank.

[16] A. Olotu, R. Salami and I. Akeremale (2015). Poverty and rate of unemployment in Nigeria. International Journal of Management, 2(1). International Journal of Business and Management. .4(6), 18-30. 